\title{
Economic Recession and a Crisis of Regulation in Safety-Critical Industries
}

\author{
Chris. W. Johnson \\ Dept. of Computing Science, University of Glasgow, Glasgow, Scotland, UK, G12 8RZ. \\ Email: johnson@dcs.gla.ac.uk \\ http://www.dcs.gla.ac.uk/ johnson
}

\begin{abstract}
Some states have knowledgeable and competent regulators. Others are less fortunate. Public safety depends upon individuals are often poorly paid compared to their colleagues in the private sector. It is difficult to attract the best people to move into regulators when state employees are paid so much less than operational staff. They lack experience and in many cases lack the motivation needed to guide the future development of safety-critical industries. There are few competency criteria for regulators. Further problems are created by cross-modal regulation. This avoids bias by ensuring that regulators do not oversee companies in industries that previously employed them. Unfortunately, this denies regulators of the detailed engineering insight that is required to understand the processes they must oversee. Many of these problems have been exacerbated by the financial crisis across Europe and North America. Fewer regulators must support a growing number of sectors. This paper describes the crisis that is facing many industries - where companies cannot obtain the guidance that they require from state agencies. Later sections propose competency criteria that can be used to assess whether regulators are fit to protect public safety across a range of different industries.
\end{abstract}

Keywords: Safety regulation, Accident Investigation, Legislation, Market Access.

\section{Introduction}

Europe and North America have come to rely on regulatory regimes that govern the design, development, operation and decommissioning of safety-critical systems. These state-funded agencies promote standards that encourage 'best practice'. They also have a role in auditing and in assessing conformance to ensure that commercial and government agencies abide by their statutory requirements. However, the last decade has seen a regulatory crisis. This paper argues that the economic recession has left many regulators with insufficient resources to meet the technical demands that are being placed on them. In consequence, highly motivated and highly skilled staff re-join commercial organisations rather than work for state agencies with limited career prospects. Financial constraints, staff shortages and technical limitations have also exacerbated the delays that arise before regulators respond to changes in safety-critical systems. In consequence, many standards are only developed in the aftermath of major accidents.

There are three primary mechanisms for achieving safety. Market forces can be used to exclude unsafe products and practices through the mechanisms of supply and demand. Unfortunately, it can be difficult to provide consumers, managers and employees with the information that is required to inform the 'rational' decisions that might drive a perfect market. In consequence, tort law provides means of redress, especially from third party risks that do not directly arise from the normal mechanisms of supply and demand. However, legal intervention is extremely inefficient. Legal costs dissuade many from pursuing justified claims. Regulation provides alternative mechanisms for promoting safety, for instance, through the development of standards that encourage good practice.

The opening sections expand this argument by comparing market forces, tort and regulation as alternate means of protecting public safety. The second half of the paper identifies the ways in which the recent financial crisis has undermined these mechanisms across Europe and North America. The 
closing sections then focuses on the regulatory crisis that threatens public safety across many different industries.

\section{Achieving Safety through the Market}

In a perfect market, there would be little need for regulation. The public would act rationally using perfect information to avoid those products and services that pose undue risk. Falling demand would lead to unsafe products being excluded from the market place. Unfortunately, we live in a world where few people understand the hazards that they face. Individuals systematically over-estimate some risks, for example, the likelihood of fatal injury from commercial aviation. Other risks are under-estimated, including the probability of suffering a stroke associated with a sedentary life style (Sjoberg, 2000).

Some of these information problems can be addressed by public education campaigns that correct misconceptions created by advertising campaigns. For instance, some low tar cigarettes are promoted as healthier alternatives to regular brands. However, commercials often fail to stress the residual risks from these products. Market forces also fail to preserve safety because many systems are so complex that people cannot understand the associated risks. It is hard for public education campaigns to provide an accurate view of potential risks without resorting to simplification. Many people are disillusioned by pages of safety-related information. There are theoretical questions about whether or not the public behave in a 'rational' way even if they are provided with reliable safety information. In many cases, deep-seated heuristics guide decision making. These may include a preference for the familiar over innovation (Beck, 1992).

Risk ambiguity creates further problems. Some products and services reduce particular risks but increase others. For example, medical drugs often reduce the symptoms of certain illnesses but increase the probability of side-effects. Clinicians must ensure that patients can provide informed consent for any subsequent treatment. In other situations, it is impossible to find clear advice on the effect that particular products might have across the risk landscape. It is also difficult for market mechanisms to address third party hazards. These arise when risks are not directly associated with consumers or suppliers. For instance, if an individual purchases a high powered car, they may be protected by a range of safety mechanisms including passenger restraints, air bags etc. The consumer of the product, the driver, would be better protected in the event of any collision than a pedestrian, a cyclist or even other motorists. Those exposed to the greatest risk play no part in the consumers' decision to purchase the product. As the potential victims were unknown to the parties involved before the accident, they could not rely on the market to protect them.

\section{Tort and Liability}

Tort law provides mechanisms to deal with third party risks. Market mechanisms cannot easily protect individuals and groups who were not involved in the consumers' decision to purchase a product. Hence, they cannot directly influence the price of a product to ensure that sufficient attention is paid to the risks it might create. In contrast, an injured third party can go to courts after an accident and expect them to determine any liability.

Tort law is retrospective; victims use it after an accident. However, there is also a deterrent element. Companies may increase their spending on safety if they are concerned about any future liability should an accident occur. The potential costs of litigation encourage organisations and individuals to take sufficient precautions to avoid an adverse event. It can also be argued that the uncertainties of the legal process encourage potential victims to behave in a safe manner. They cannot assume that they will be adequately compensated after costly litigation; hence individuals will try to reduce the likelihood of becoming involved in an accident. 
The distinctions between the market and the role of tort in consumer safety have become increasingly blurred. For example, insurance markets provide suppliers and manufacturers with financial protection from litigation. This creates a situation in which the actuarial pricing of policies indirectly determines whether or not particular products or services are brought to market. Suppliers may decide not to provide some goods because they cannot afford insurance premiums to offset the potential costs of litigation. Later sections will describe how regulators have increasingly been drawn into these interactions, where they attempt to set the price of insurance and restrict tort liability to ensure that the public can still obtain key services, such as obstetric cover in the face of rising costs from medical litigation.

Tort law has been extended from situations in which the victims were unknown to the consumer and supplier prior to an accident. It is now applied more generally in cases of malpractice. Tort can also be used to claim redress in cases of product liability where an individual purchases a good or service from a particular supplier. These developments have created closer links between the legal system and the insurance market. Suppliers and consumers create contracts prior to purchase that limit the liability in case of an adverse event. Typically, this liability is closely tied to the extent of any insurance cover. The premiums associated with this level of protection are then factored into the purchase price so that the consumer eventually meets the costs of protection or decides not to buy the product.

Unfortunately, tort law is inefficient. The costs associated with litigation deter many people with justified claims. In contrast, 'no win-no fee' litigation has persuaded many companies to settle out of court rather than risk the costs associated with lengthy court cases. A significant proportion of the expenses associated with tort cases support the legal infrastructure rather than providing relief to an injured party. This is particularly significant in litigation involving risk ambiguity; where products decrease one form of risk and increase others. In such circumstance, lawyers spend many weeks determining liability. It is often unclear whether a medical drug caused an adverse reaction when a patient was, by definition, already suffering from an illness. Some jurisdictions have tried to introduce the concept of 'net harm' to deal with such complexities. However, this creates further points for litigation to demonstrate that any negative effects can be offset against the benefits of a product or service.

There are further problems in the use of tort to promote safety. As mentioned previous, this form of litigation encourages suppliers to take out insurance that will help to cover potential claims. However, such policies can reduce the moral disincentive to engage in high risk activities. Companies may be less concerned about future injuries because they know that they have sufficient insurance. Imperfections in the insurance market can persuade companies to discount the costs associated with any consequent litigation. Third, the costs of litigation may create imperfections in the market regulation of risk. For example, companies can be dissuaded from carrying out the development work on new products or services if their potential liabilities are considered to be too high even when the proposed innovation may act to reduce long term risk.

\section{The Role of Safety Regulation}

We cannot rely upon the market or upon tort law to ensure public safety. Market forces cannot guarantee safety because consumers lack perfect knowledge about the risks they face and market forces fail to account for third party effects. Tort law is costly and forces companies to use (imperfect) insurance markets as a means of offsetting their risk exposure. Spurious litigation increases the costs of premiums that act as a disincentive for companies to enter many markets. These limitations justify state intervention in the regulation of safety-critical industries.

Safety regulation depends on the creation of standards to assess whether the processes used by an organisation or the products they create are acceptably safe. Criminal liability can be associated with products or processes that fail to meet these minimum requirements. For example, the US Code of 
Federal Regulations (16 CFR 1303) bans the use of lead paint in toys or furniture to reduce the risks from children ingesting this potentially toxic material. Regulators can also set performance standards, without stating how these requirements are to be met. For instance, the Code of Federal Regulations (40 CFR 68) requires that companies which use or store highly hazardous chemicals must follow the US Occupational Health and Safety Administrations Process Safety Management (PSM) regulations.

Information regulation seeks to address the lack of data that is often cited as a limiting factor on rational decision making within safety-critical markets. In other words, regulators ensure that customers have access to sufficient information to make an informed choice. This depends on the credibility of the data. Consumer confidence is often undermined when companies and safety regulators over-estimate the safety of a product. In many situations, regulatory agencies lack sufficient information to assess the risks associated with safety-critical processes, especially for new industries without an established safety record. This creates conflict when public bodies adopt a precautionary approach that rejects levels of risk which would otherwise be acceptable to commercial organisations. Companies and consumers criticise regulators that are seen to place unnecessary restrictions on safety-critical industries.

There are many other ways in which companies can influence regulatory policy. The International Organization for Standardization (ISO) and the American National Standards Institute (ANSI) rely on technical input and expertise from private organisations as well as government agencies. Commercial participation in the development of voluntary standards also helps to ensure that changes are implemented more quickly than through legislation and enforcement. However, commercial participation can also be used to reinforce the status quo. Standards create barriers to market entry when competitors struggle to understand complex, safety requirements with little supporting guidance.

Regulation and tort are typically employed together. Tort provides a framework for assessing liability after an adverse event. Whereas inspections and reviews can be used to determine compliance with standards before an accident takes place. However, successful regulation depends upon the competency and independence of the individuals who conduct these audits.

\section{The Crisis in Safety Regulation}

Limitations in the free market and in tort law help to explain the need for state intervention in the regulation of safety-critical industries. The extent to which any country relies on each of these approaches is determined more by political influence than by technical arguments. The following sections show how the political response to economic recession across Europe and North America has contributed to a crisis in safety regulation.

\subsection{Regulation during a Recession}

The economies of most European and North America countries have experiences significant problems following the loss of confidence and liquidity in the 'credit crunch'. This was triggered by the need for banks to rebuild balance sheets after losses sustained from sub-prime mortgages in August 2007. The knock-on effects included a sudden need for governments to assist in the recapitalisation of their banking sectors. This led to an increase in public borrowing and with it a pressing need to control other forms of government spending in order to address rising levels of debt. At the same time, there was a crisis of confidence in the banking sector with lenders refusing to issue loans that might be interpreted as exposing them to risks similar to those accepted before 2007. Increasing uncertainty about the health of the global economy, concern over a perceived failure to address government debt and limited access to loans all had knock-on effects for securities. This created a negative multiplier; government spending was cut while private enterprise found it hard to access the capital that might have fuelled a recovery. This, in turn, starved governments of income from additional taxation during the recession. Between 2010 and 2012, the UK construction industry contracted by some 5\%. The 
number of public houses built fell by $18 \%$ in the twelve months before July 2012 . Public non-housing construction fell by $21 \%$ between the first quarter of 2011 and 2012 .

The recession has a complex impact on safety. Fewer workers are exposed to the hazards of high-risk industries. At the same time, there are fewer resources available to spend on corporate health and safety initiatives. In times of recession with reduced levels of demand and increasing supply-side competition there is a temptation to cut any expenditure that cannot be directly shown to support revenue. Economic pressures can undermine safety when fewer people are expected perform more tasks. For example, the UK Ministry of Defence's head of Nuclear Safety argued that "Inadequacy of resources, both money and staff complement, and the difficulties in maintaining a sustainable cadre of suitably competent staff are the principal threats to safety in the defence nuclear programme in the medium term" (UK MOD, 2012). It is difficult to ensure that redundancies do not remove significant experience from safety-critical operations.

The statistics on work place safety do not show any clear rise in the numbers of incidents and accidents (HSE, 2011). Although there was a rise in fatal injuries between 2009 (104) and 2011 (120), there has been a significant fall since 2006 (191). At the same time, there has also been a fall in the number of HSE prosecution cases resulting in at least one conviction from 517 in England and Wales (2006-7) to 484 (2010-11). A number of alternate hypotheses can be used to explain these ambiguous statistics:

- There may have been an increase in safety during the recession;

- Or redundancies may have reduced exposure to some hazards as the economy contracts;

- Or cuts in funding to the regulatory agencies may have limited health and safety prosecutions.

Between the first quarter of 2011 and 2012, UK government borrowing fell by some $£ 10$ billion; this was achieved through stringent cuts in spending. Lord Young's Common Sense, Common Safety report (UK Government, 2010) addressed tort reform; "a 'compensation culture' driven by litigation is at the heart of the problems that so beset health and safety today". However, the review also recommended a series of exemptions from risk based regulation in 'low hazard businesses'. The Chair of the Health and Safety Executive welcomed the review but also addressed criticisms that government cuts in her budget would have a negative effect on safety:

"The HSE has of course had to take its share of savings just as any other Government department or public body. The settlement has been publicised already and the headline figures are that HSE is required to make a minimum of 35 per cent savings in its dependence on public funding over four years. But let's put that into context. Savings of 35 per cent are the norm across Department of Work and Pensions - our sponsoring department. So we are not being treated more harshly than anyone else"(Hackett, 2010)

Concerns that spending cuts will limit the effectiveness of Health and Safety regulators are not confined to the UK. In 2007-8 the Canadian government had reviewed plans to alter the balance between free-market and regulatory approaches to safety. Proposals were made to reduce intervention from Federal food safety inspectors and allow companies to implement their own means of meeting hygiene and safety standards. These plans had to be shelved in the face of public pressure after 22 people died during a listeriosis outbreak in New York, Ontario. However, further financial pressures following the economic downturn led the government to request $\$ 56$ million of savings from the Canadian Food Inspection Agency, bringing more than 100 posts into question over the next three years.

\subsection{Regulation and Market Access}

Health and safety legislation can be (ab)used as a means of protecting domestic markets. European railways provide numerous examples. For instance, the European Commission has created interoperability directives (eg 2008/57/EC). These have been augmented by recommendations on the authorisation of subsystems and vehicles with the ultimate aim of encouraging cross-acceptance. In 
other words, if a rail vehicle is authorised in one member state it should be relatively straight-forward to achieve acceptance in another member state. Unfortunately, much remains to be done. The 2011 European Railway Agency (ERA) Report on Railway Vehicle Authorisation estimated that achieving acceptance across more than 20 different national systems would cost the industry more than $€ 400$ million over the next fifteen years:

"In the next 15 years about 35 new different types of locomotives and 15 new fixed trainformations will be developed. Each type of locomotive and fixed train formation will require an additional authorisation in $10 \mathrm{MSs}$ (=500 additional authorisations). The average costs for receiving one additional authorisation were estimated to be $1600 \mathrm{k} €$ (which is in line with the feedback from the questionnaire). A "perfect" cross acceptance may reduce the costs of an additional authorisation by $50 \%(800 \mathrm{k} €)$ " (ERA, 2011)

ERA concluded that "the Sector has not yet seen the benefits and reduced costs that come from replacing 27 national approaches to authorisation with one common approach envisaged by the Directive 2008/57". It can take from 18 months to 3 years to achieve approval in each national system. Further problems arise when the procedures that must be followed in order to achieve authorisation are not always made explicit to applicants from other countries. European agencies concerned with improved market access repeatedly refer to the problems of transparency in safety regulation, "New entrants to a Member State have particular difficulties because they will not be aware of local "custom and practice" if it is not documented as a rule. It should be noted that even where rules exist not all of them are notified. The level of detail of the requirements differs between countries (ERA, 2011)". In some cases, there remains a suspicion that safety regulations are being actively used as a barrier to market access. In other states, the incompatibilities or discontinuities in regulatory approach reflect deeper confusion about their obligations under the European Railway Safety and Interoperability Directives.

\subsection{Competency and Multi-Modal Regulation}

Many countries lack explicit competency requirements for their safety regulators (Department for Business Enterprise and Regulatory Reform, 2007). There are no international criteria that help to ensure the mutual recognition of regulatory expertise between countries. From this it follows, that regulators cannot easily work in different countries; even within the European Community where national legislation implements a common core of safety directives. This creates an inelastic supply and builds barriers to the exchange of expertise between regulatory agencies in different countries.

Some governments now employ multi-modal regulators who help to enforce policies and procedures across many diverse industries. In preparing this paper, the author met with a regulator whose training was in food safety but who had been redeployed to air traffic management without any formal training in the underlying systems engineering. It takes many years for individuals to build up sufficient expertise to understand safety-critical industries. Of course, this creates a danger that regulators will form close working relationships with the companies that they support. Equally we are now in a situation where most regulatory agencies have a significant competency gap in terms of technical understanding; they rely almost entirely on industry to explain and interpret the processes that are being used within many key areas. More worryingly, engineers and managers have a growing distrust of regulators who fail to understand the basic technologies they help to regulate.

The last decade has seen the development of professional regulators; who have specific competency in the regulatory process rather than in the particular industries that they support. For example, the UK government has a Statutory Code of Practice for Regulators (BERR, 2007). This is intended "to embed a risk-based, proportionate and targeted approach to regulatory inspection and enforcement among the regulators it applies to". The aim is to focus finite resources on problem areas without inconveniencing low risk, compliant firms. The code of practice says nothing about the technical competency of regulators. Similarly, HSE Guidance for Regulatory Staff on the Practice of Assessing 
Health and Safety Management focuses on core skills that can be applied irrespective of the technical areas that are being regulated. This creates significant concerns when the companies at the leading edge of technical innovation require guidance from the government agencies that regulate their industries. By focusing on competency in regulation without adequate technical expertise, there is a danger that government agencies will lack the necessary skills to ensure public safety.

\subsection{The Impact of Economic Dislocation and Disruptive Technologies}

The recession has had different effects across different safety-critical industries. Redundancies in construction and manufacturing have been partially offset by a rising demand for skills in other areas, such as renewable energy systems. These structural changes in the economies of Europe and North America have exposed some workers to new hazards. At the same time, other risks have declined with fewer workers employed in some industries. These structural changes create new challenges for regulators; who must tailor their intervention to the new risk landscape

The impact of the recession has been compounded by technological change. For example, cyberattacks pose a growing threat to the safety of complex systems (Johnson, 2012). We cannot close down an air traffic system leaving aircraft in flight when malware is detected. Very few people have the technical and managerial skills to assess the extent of this problem. A further example is provided by the integration of Unmanned Aerial Systems into conventionally controlled civil air space. Few people have the necessary technical skills to identify the safety implications of such disruptive technologies - or to identify appropriate mitigations for new classes of risks when air traffic controllers have to coordinate pilots and ground controllers thousands of miles away. Similar comments can be made about Global Navigation Satellite Systems. Demand for relevant skills has risen rapidly since both Europe and North America have approved Satellite Based Augmentation Systems for use in safety-critical applications across the rail, maritime and aviation sectors.

It takes time to train sufficient numbers of people to address new safety concerns. Universities and other profession bodies are relatively slow to respond to these new demands - it can take more than twelve months to approve a new course of study and then a further 3-4 years before the first graduates appear on the labour market. Many of these institutions act in a conservative fashion. It can take government prompting before they acknowledge the need to provide explicit support for the labour market. Once students have graduated, they then have to gain the experience that is necessary before they are competent. In the meantime, companies and regulators struggle to obtain sufficient expertise to mitigate a new generation of hazards. Regulatory bodies have little chance of recruiting sufficient expertise to ensure the safety of disruptive technologies during a recession when there is increased pressure to meet government spending targets. European regulators are prevented from recruiting staff in order to reduce public borrowing requirements. We have, therefore, reached a situation where previous generations of regulator are struggling to respond to disruptive technologies that have introduced a new generation of safety hazards.

\subsection{The Balance between Safety Regulations, Insurance and New Market Opportunities}

The economic downturn since 2004 has focussed attention on national safety regulations that inhibit the growth of new markets. This can be illustrated by concerns over the role of regulation, tort and insurance in space operations (UK Space Agency, 2012). The UK Outer Space Act (1986) creates unlimited liability from UK companies. They were required to obtain third party liability insurance of $£ 100$ million for both the launch and in-orbit phases of a mission. However, the costs associated with these insurance policies dissuaded many companies from entering the market. Insurance companies had insufficient experience of these risks and hence took a conservative approach when setting their premiums (US FAA, 2002). In contrast, liabilities have been capped in the UK nuclear and off-shore oil/gas industries. These potential liabilities and insurance requirements were also perceived to undermine national competitiveness. The United States, Russia, China etc. do not require any insurance for the operators of a space mission. In consequence, the UK Minister for Universities and Science reduced compulsory insurance to $€ 60$ million. He also launched an initiative to cap unlimited liabilities to $€ 60$ million for most missions. By comparison, the ceiling for nuclear incidents is $£ 140$ 
million. The UK government must meet any remaining liabilities under the UN Treaty on Outer Space.

The supporting analysis that was published along with the proposals for the revision of UK space policy did note that the transfer of third party risk from private operators to the Government might create a 'moral hazard'. Private satellite operators would have less incentive to mitigate the risk of an accident that might lead to third party claims. This would in turn increase the probability of an incident. The proponents of the change argued that this moral hazard would be mitigated by stringent analysis prior to launch. As we have seen, however, significant questions remain about the resources, both human and financial, to conduct such analyses at a time of financial stringency across government safety agencies.

\section{Conclusion and Further Work}

Previous sections have argued that we cannot rely upon market forces to guarantee the safety of complex systems. Consumers often lack the information and technical insight in order to make informed decisions about the products that they buy. The market fails to account for third-party hazards; these affect people who neither consumed nor supplied a product. Tort law provides means of redress, offering compensation to a claimant. In extreme cases, punitive damages may also be used to deter others from repeating similar breaches of safety. Unfortunately, tort law is usually applied after an accident has occurred ${ }^{1}$. Insurance protects companies against subsequent liabilities; this erodes the moral hazard that might motivate safety innovations before a mishap occurs. Tort is inefficient, with resources being used to maintain the legal system rather than being spent on safety improvements. Finally, the system can be abused by plaintiffs raising spurious cases in the hope of securing compensation. This raises premiums to the point where it is uneconomic to offer services and products with a high social value. Other mechanisms are, therefore, needed to protect public safety.

Regulation supplements market forces and tort law. Government agencies help draft standards that guide the development and operation of safety-critical processes. Unlike tort, regulators intervene before an accident occurs. They disseminate best practice and censure companies that violate minimum requirements. However, regulators introduce additional costs if standards are not supported by evidence that shows a clear contribution to safety. Further problems arise when regulators lack the necessary competence to provide clear guidance to companies seeking their support.

Most countries continually alter the balance between regulation, tort law and the free operation of market forces. In many cases there is an iterative cycle in which major accidents motivate increased regulation. After a few years, regulatory intervention is relaxed to encourage growth. Politicians respond to criticisms of a 'health and safety culture' that is perceived to place unnecessary constraints on individual freedoms. The economic recession starting in 2007 has accelerated these processes as many governments seek to reduce public spending on regulatory agencies. However, this loss of regulatory supervision is creating the preconditions for future accidents.

Funding cuts have forced regulatory agencies to restrict their activities - by introducing 'light weight' approaches to safety regulation and 'risk based' techniques that focus finite resources. This creates significant safety concerns because many agencies lack staff that are competent to apply these approaches. It is increasingly difficult for government bodies to recruit and retain specialists in the disruptive technologies that arguably pose the greatest risks to public safety. The development of multi-modal regulators and the "profession of safety regulation" undermine the technical skills that are necessary to understand future hazards in complex systems.

\footnotetext{
${ }^{1}$ Speculative damages are an exception. However, the plaintiff must prove that an act is reasonably likely to lead to future losses.
} 
Financial stringency, disruptive technologies and changing markets challenge the regulation of safetycritical industries. New infrastructures, new production techniques, new operating procedures create hazards that previous generations of regulators are ill-equipped to deal with. In consequence, companies lack regulatory guidance in many areas. They are forced to engage with teams that lack the technical expertise to know whether or not proposals are admissible under an existing regulatory regime. Equally governments lack the advice they need when obsolete legislation must be ammended to maintain safety and open up new market opportunities. Examples include the integration of UAVs into civil controlled air space, different regulatory requirements on the operation of satellites, the unified approval mechanisms for railway vehicles, concerns over the provision of food safety inspectors etc.

These criticisms do not apply to all regulatory agencies. However, these problems can be seen across many industries in both Europe and North America. There is an urgent need to respond - for instance, by reviewing competency requirements for safety regulators and by ensuring compliance with the same rigour that might be used in ensuring the compliance of operators to safety regulations. It is unrealistic to expect that the financial constraints will be eased in the short term. There is, therefore, a need to carefully monitor accident and incident rates to minimise the impact of cuts on public safety. Finally, steps must be taken to review the core technical expertise that regulators will need in the next decade. Key weaknesses, in particular in software engineering, cannot be compensated by 'professional regulators' who do not understand the basic concepts of these enabling technologies.

\section{References}

U. Beck, Risk Society, Towards a New Modernity. London, UK, Sage Publications. 1992.

Department for Business Enterprise and Regulatory Reform, Regulators' Compliance Code, Statutory Code of Practice for Regulators, London, UK, December 2007. Available from http://www.berr.gov.uk/files/file45019.pdf

European Railway Agency (ERA), Report on Railway Vehicle Authorisation, Part 1: The Current Situation, Report ERA/REP/2011- 01/XAC, Valenciennes, France, April 2011.

J. Hackitt CBE, HSE Chair, Health and Safety after the Young Review: The future of health and safety from HSE's perspective, Bootle, Merseyside, UK. Available from:

http://www.hse.gov.uk/aboutus/speeches/transcripts/hackitt071210.htm

C.W. Johnson, Preparing for Cyber-Attacks on Air Traffic Management Infrastructures: Cyber-Safety Scenario Generation. In Proceedings of the 7th IET Conference on Systems Safety and CyberSecurity, Edinburgh, Scotland, 15-18 October 2012, IET, Savoy Place, London, 2012.

L. Sjoberg, Factors in Risk Perception, Risk Analysis, (20)1:1-11, 2000.

UK Government, Lord Young of Graffham; Common Sense, Common Safety, UK Government, London, UK, 2010. Available from:

http://www.number10.gov.uk/wp-content/uploads/402906_CommonSense_acc.pdf

UK Health and Safety Executive, Health and Safety Executive Annual Statistics Report, Bootle, Merseyside, UK, 2011. Available on: http://www.hse.gov.uk/statistics/overall/hssh1011.pdf

UK Ministry of Defence, Defence Nuclear Safety Regulator: Defence Nuclear Environment and Safety Board Assurance Reports, London, UK, July 2012. Available from:

http://www.mod.uk/DefenceInternet/AboutDefence/CorporatePublications/HealthandSafetyPublicatio ns/DSEA/DefenceNuclearEnvironmentAndSafetyBoardAssuranceReports.htm 
UK Space Agency, Reform of the Outer Space Act 1986: Consultation, URN 12/819, Polaris House, Swindon, UK, 31 May 2012. Available from: http://www.bis.gov.uk/ukspaceagency/news-andevents/2012/May/reform-of-the-outer-space-act-1986-consultation

US Federal Aviation Administration, Liability risk sharing regime for US Commercial Space Transportation, Washington DC, USA, 2002. Available from:

http://www.faa.gov/about/office_org/headquarters_offices/ast/media/FAALiabilityRiskSharing402.pdf 